\title{
Routine use of recombinant human bone morphogenetic protein-2 in posterior fusions of the pediatric spine and incidence of cancer
}

\author{
Christina Sayama, MD, MPH, ${ }^{1,2}$ Matthew Willsey, BS, ${ }^{1,2}$ Murali Chintagumpala, MD, ${ }^{3}$ \\ Alison Brayton, RN, ${ }^{1,2}$ Valentina Briceño, RN, ${ }^{1,2}$ Sheila L. Ryan, JD, MPH, ${ }^{1,2}$ \\ Thomas G. Luerssen, MD, ${ }^{1,2}$ Steven W. Hwang, MD, ${ }^{4,5}$ and Andrew Jea, MD ${ }^{1,2}$

\begin{abstract}
${ }^{1}$ Neuro-Spine Program, Division of Pediatric Neurosurgery, and ${ }^{3}$ Neuro-oncology Program, Division of Hematology-Oncology, Department of Pediatrics, Texas Children's Hospital; and 'Department of Neurosurgery, Baylor College of Medicine, Houston, Texas; ${ }^{4}$ Division of Pediatric Neurosurgery, Floating Children's Hospital; and ${ }^{5}$ Department of Neurosurgery, Tufts University, Boston, Massachusetts
\end{abstract}

OBJECT The aim of this study was to determine the safety of recombinant human bone morphogenetic protein-2 (rhBMP-2) use in posterior instrumented fusions in the pediatric population, focusing on cancer risk. In a previous study, the authors reported the short-term (mean follow-up of 11 months) safety and efficacy of rhBMP-2 in the pediatric age group. The present study reports their results with a minimum of 24 months' follow-up.

METHODS The authors retrospectively reviewed 57 consecutive cases involving pediatric patients who underwent posterior occiptocervical, cervical, thoracic, lumbar, or lumbosacral spine fusion from October 1, 2007, to June 30, 2011, at Texas Children's Hospital. Seven cases were excluded from further analysis because of loss to follow-up. Three patients died during the follow-up period and were placed in a separate cohort.

RESULTS The patients' average age at the time of surgery was 11 years, 4 months (range 9 months to 20 years). The mean duration of follow-up was 48.4 months (range 24-70 months). Cancer status was determined at the most recent encounter with the patient and/or caretaker(s) in person, or in telephone follow-up. Twenty-four or more months after administration of rhBMP-2, there were no cases of new malignancy, degeneration, or metastasis of existing tumors. The cause of death of the patients who died during the study period was not related to BMP or to the development, degeneration, or metastasis of cancer.

CONCLUSIONS Despite the large number of adult studies reporting increased cancer risk associated with BMP use, the authors' outcomes with rhBMP-2 in the pediatric population suggest that it is a safe adjunct to posterior spine fusions of the occipitocervical, cervical, thoracic, lumbar, and lumbosacral spine. There were no new cases of cancer, or degeneration or metastasis of existing malignancies in this series.

http://thejns.org/doi/abs/10.3171/2014.10.PEDS14199

KEY WORDS bone morphogenetic protein; pediatric spine; spinal instrumentation; cancer; complications; malignancy; neurosurgery; spinal fusion; rhBMP-2; oncology; technique

$\mathrm{T}$ HE use of autograft bone to achieve a spinal fusion is the gold standard by which all other grafting materials are judged. Its dependable rate of incorporation leading to a successful spinal arthrodesis has been documented. ${ }^{11}$ The potential benefits of using recombinant human bone morphogenetic protein-2 (rhBMP-2) over autograft or allograft bone are numerous. These may include decreased operative time, blood loss, donor-site morbidity, ${ }^{5}$ transmission of infection associated with use of al- lograft, ${ }^{2}$ and rate of pseudarthrosis. ${ }^{6}$ In addition, its unlimited quantity and immediate availability make rhBMP-2 useful in certain pediatric spine applications, although its cost may be prohibitive in some settings. There are concerns regarding the routine and "off-label" substitution or supplementation of autologous or allograft bone graft with rhBMP-2. Significant concerns involve the possibility of bony overgrowth, interaction with exposed dura, systemic toxicity, local toxicity, immunogenicity, osteoclastic acti- 
vation, and effects on distal organs; the most serious concern has been the implication of BMP in the development of new cancers. ${ }^{31}$

As a growth factor, BMP has the potential to affect processes regulating cell division. Consequently, there has been concern that BMP may contribute to tumorigenesis, tumor degeneration, and metastasis. During the premarket approval application for a higher dose of rhBMP-2 (40 mg) (AMPLIFY; Medtronic Sofamor Danek), the risk of cancer was greater in the rhBMP-2 group compared with the control group..$^{10}$ The FDA consequently denied approval.

We previously reported our experience with the routine use of BMP in pediatric spine surgery. ${ }^{14}$ In that study, we focused on the early postoperative complications related to BMP use. The follow-up was short (mean 11 months) and did not afford us an opportunity to analyze complications such as incidence of new cancer in long-term follow-up. The purpose of the present study is to examine the longterm incidence of cancer after posterior occipitocervical, cervical, thoracic, lumbar, or lumbosacral spine fusion using rhBMP-2 in pediatric patients after a mean follow-up of 48.4 months. To the best of our knowledge, this is, to date, the largest pediatric study of outcomes with at least 2 years of follow-up following rhBMP-2 administration.

\section{Methods}

We retrospectively reviewed the charts of 57 consecutive pediatric patients who underwent posterior occipitocervical, cervical, thoracic, lumbar, or lumbosacral spine fusions with rhBMP-2 from October 1, 2007, to June 30, 2011, at Texas Children's Hospital. Seven patients were excluded from the analysis because they were lost to follow-up and we were unable to obtain current information about them, and 3 patients died during the follow-up period, thus leaving 47 cases for our primary analysis (Table 1). The 3 cases involving patients who died were analyzed separately (Table 2).

The study group included 24 girls and 23 boys, and their age at surgery ranged from 0 years, 9 months to 20 years, 0 months, (mean age 11 years, 4 months). The minimum duration of follow-up was 24 months (mean 48.4 months, range 24-70 months). We recorded patient demographics; perioperative data, including dose of BMP; and outcome, including the development of cancer and other complications related to BMP (Table 1).

Follow-up consisted of clinic visits (33 patients), and if the patient had not been seen in 12 months, a telephone call asking the patient and/or parents/caregivers whether there were any other medical problems, such as cancer, that had developed and been diagnosed between this encounter and the previous encounter (14 patients). The rationale for this method of cancer case detection is that it is simple, low cost, and does not entail increased radiation exposure to the child. We consulted the chief of the neurooncology program at Texas Children's Hospital (M.C.) to ask about screening CT or PET scans to look for cancer in this cohort, and as there is not yet any proven association between BMP and cancer, there is little justification for screening tests.

We repeatedly attempted to contact patients lost to follow-up via telephone calls, voicemail messages, and emails. Moreover, we performed a Worldwide Web search on all the patients lost to follow-up to ensure that there were no obituaries that would indicate death; in 1 case, the patient's death was found in this manner.

Of the 3 patients who died during the follow-up period, 2 died within 13 months of surgery (at 13 months and 1.5 months postoperatively), and the third died 5 years, 9 months after surgery. None of these patients had developed cancer at the time of death. Their mean age at the time of death was 8 years, 8 months (range 1 year, 7 months to 20 years, 9 months). The cause of death, and autopsy findings if available, were recorded (Table 2).

\section{Surgical Technique}

The senior author (A.J.) was the attending surgeon for all spine surgeries. The surgery consisted of routine exposure of the spine over the entire length to be instrumented. Placement of segmental instrumentation, if performed, was done in standard fashion. Decortication of the laminae, spinous processes, and facet joints was performed using a matchstick bur after placement of spinal instrumentation.

\section{BMP Dosing}

Increments of small $(2.8 \mathrm{mg})$, medium $(5.6 \mathrm{mg})$, and large $(8.0 \mathrm{mg})$ kits of rhBMP-2 were used in each case and applied on a collagen sponge (INFUSE, Medtronic Sofamor Danek). The collagen sponges were generally cut into 1-cm strips and placed in a single layer overlying the posterior elements after thorough decortication of the bone. The amount of rhBMP-2 was determined intraoperatively, depending on the surface area of the intended fusion levels.

\section{Use of Bone Graft}

The rhBMP-2 was applied as described above along with some form of bone graft autograft, morselized cancellous bone allograft, and/or demineralized bone matrix (MasterGraft Matrix, Medtronic Sofamor Danek). In 25 patients, the rhBMP-2 was used with only allograft (demineralized bone matrix and/or morselized cancellous allograft). The rhBMP-2 was applied with autograft and allograft in 14 patients. In 8 patients, it was used with autograft alone.

Local autograft was used whenever it was available. If the quantity of locally available autograft was insufficient to adequately cover the fusion area, it was supplemented with either allograft (most commonly) or demineralized bone matrix. We abandoned the practice of harvesting iliac crest (or rib) autograft due to the associated morbidities. Harvest of autograft from separate donor sites, such as the iliac crest or rib, was performed in only 2 patients in our cohort.

\section{Follow-Up}

Patients were seen in clinic at 2 weeks, 6 weeks, and 3,6 , and 12 months after surgery and annually thereafter. For the purposes of this study, patients and caretaker(s) were brought back to the clinic off schedule for assessment of the development of cancer, or were questioned via telephone follow-up by a clinical neurosurgery nurse. 


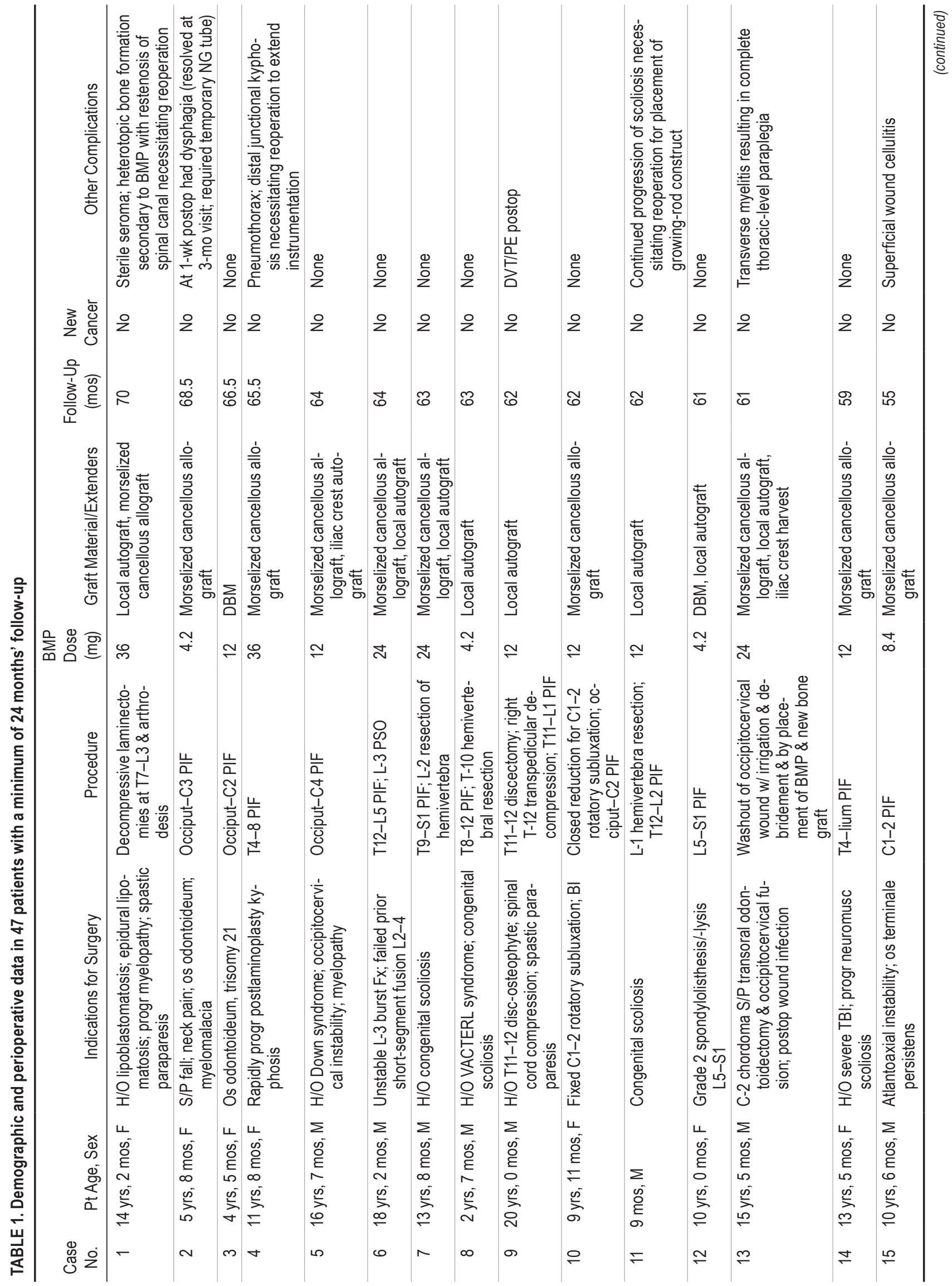




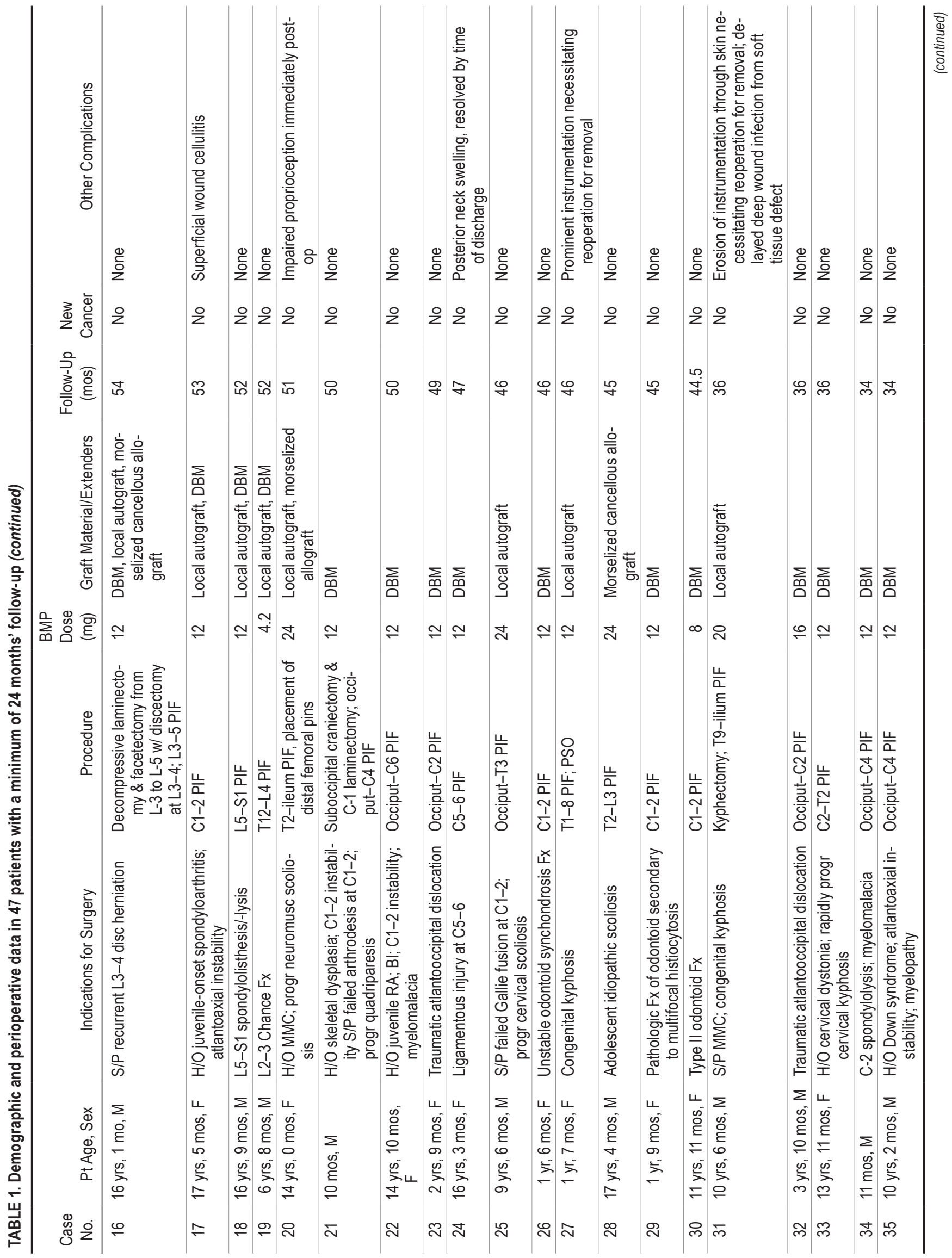




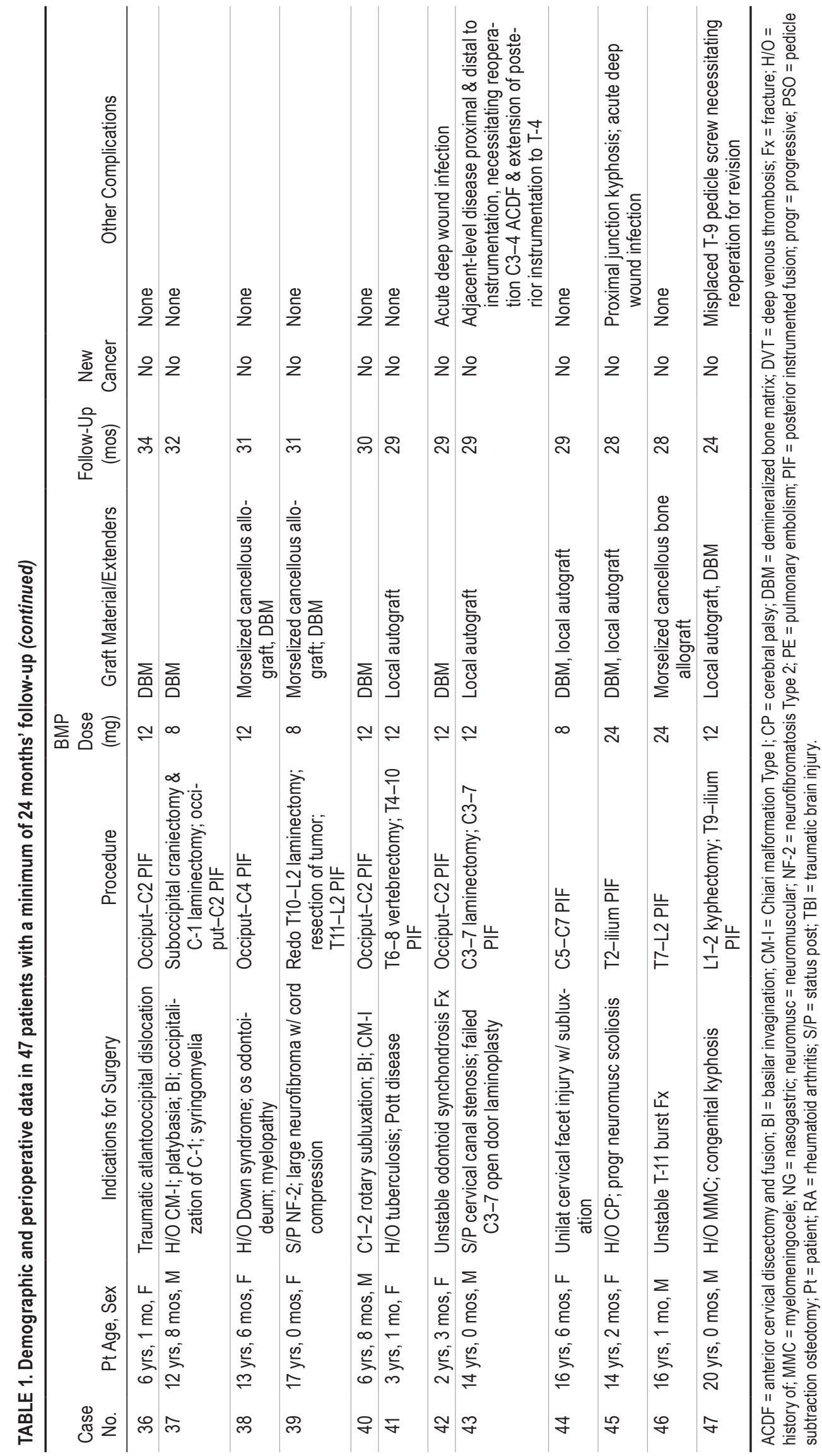




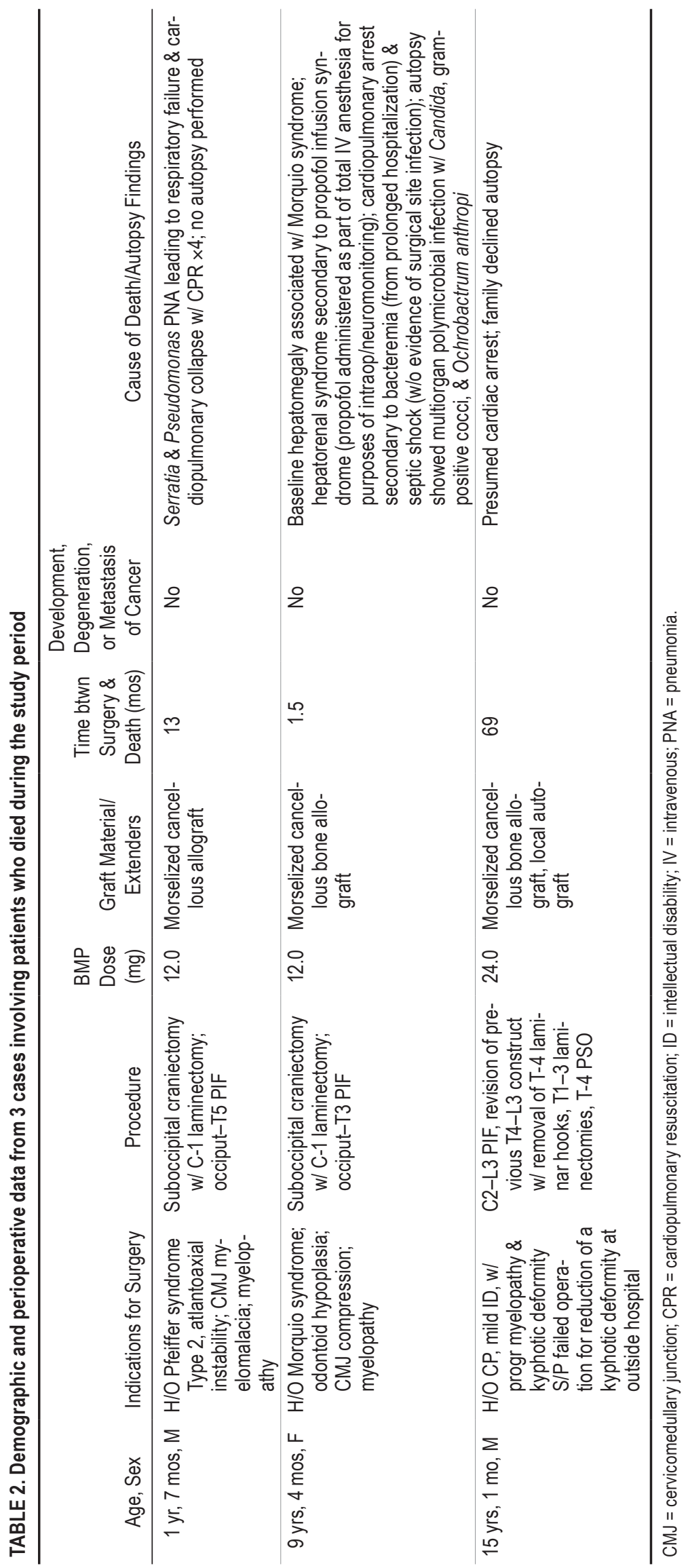

J Neurosurg Pediatr Volume 16 • July 2015 


\section{Results}

There were no cases of new cancers, degeneration, or metastasis of existing malignancies in our cohort of patients (95\% CI 0\%-7.6\%, Wilson score interval). The mean duration of follow-up was 48.4 months across the range of doses of BMP administered (4.2-36 mg, mean $14.4 \mathrm{mg}$ ). Three patients had preexisting tumors, including lipoblastomatosis (1 case), chordoma (1 case), and neurofibroma (1 case). Seven patients (12.3\%) were lost to follow-up despite repeated attempts to contact them.

In the separate cohort of deceased patients, the cause of death was unrelated to BMP use and the development, degeneration, or metastasis of cancer. One patient with a history of Pfeiffer syndrome and restrictive lung disease died 13 months after surgery from pneumonia and respiratory failure.

A second patient, who had Morquio syndrome, baseline hepatosplenomegaly, and chronic hepatitis, died 1.5 months after surgery from propofol infusion syndrome. Propofol infusion syndrome is a rare and frequently fatal complication of propofol infusion at high doses; it is characterized by metabolic acidosis, rhabdomyolysis of both skeletal and cardiac muscle, arrhythmias (bradycardia, atrial fibrillation, ventricular and supraventricular tachycardia, bundle branch block, and asystole), myocardial failure, renal failure, hepatomegaly, and death. Our patient developed worsening metabolic acidosis, myocardial failure, hepatomegaly and hepatic failure, and renal failure over a 5-day course after surgery; she had been given significant doses of propofol as part of total intravenous anesthesia in a standard regimen for intraoperative monitoring of motor evoked potentials. She ultimately succumbed to multiorgan failure and sepsis after a prolonged 1-month stay in the intensive care unit.

A third patient had a history of cerebral palsy, developmental delay, and spinal cord injury secondary to a worsening kyphotic deformity. He was initially operated on at an outside hospital; the upper part of the construct failed, resulting in proximal junction kyphosis. We subsequently performed a pedicle subtraction osteotomy and extended his fusion to treat his deformity and stenosis. He died 5 years, 9 months after his initial surgery due to a presumed cardiac arrest. His parents reported no development of cancer in the period from surgery to his untimely passing, but they declined an autopsy.

\section{Discussion}

The osteoinductive role of rhBMP-2 is multifaceted, as it acts as a chemotactic agent, a growth factor, and differentiation factor. ${ }^{38}$ The FDA has approved rhBMP-2 as the first complete bone graft substitute for anterior interbody fusions of the adult lumbar spine..$^{15}$ In clinical trials, authors have demonstrated the usefulness of rhBMP-2 for single-level anterior interbody fusion of the adult lumbar spine, resulting in greater radiographic fusion rates, improved pain and function scores on the Oswestry Disability Index, and higher overall clinical success over traditional bone grafting techniques. ${ }^{3,5}$

Although the FDA has only approved the use of rhBMP-2-soaked absorbable collagen sponges for use in adult anterior interbody lumbar fusion, "off-label" appli- cations have been reported. ${ }^{9,27}$ We previously reported the early safety and efficacy of rhBMP-2 use for posterior spinal fusions in the pediatric population (mean follow-up of 11 months). ${ }^{14}$

\section{Advantages}

Biomechanically, the rhBMP-2-generated fusion mass is superior at 3 months, as compared with that generated by autograft. ${ }^{32,33}$ Findings have shown the fusion mass to be more mature, with more advanced remodeling and marrow formation, than that generated by autograft alone. In our previous study, ${ }^{14}$ we did not expect to find large mature fusion masses (Grade 4) in our posterior spine fusions in the early postoperative period, but this occurred in 2 patients $(10.5 \%)$. Bone healing and remodeling may take up to $12-24$ months. ${ }^{11}$ However, we did expect to see advanced bone healing, at least in the form of bilateral stable bridging bone (Grades 3-, 3, 4-, and 4), across the segment of spine where we laid down rhBMP-2 and bone graft/graft extenders, and this was observed in $16(84.2 \%)$ patients.

Another advantage of rhBMP-2 is its potential role in promoting fusion in very young children. Our present study included 8 patients younger than 3 years of age at the time of surgery; we found these patients to have a very limited amount of bone available for autograft harvest without adding morbidity. In these cases, the ability to promote fusion by adding rhBMP-2 is advantageous.

The historically published fusion rates achieved with autograft alone are similarly high when compared with fusion rates achieved with BMP and allograft in children. The use of BMP, however, has allowed us to avoid a separate site of surgery to harvest autograft. In a young child, harvesting rib graft or iliac crest graft is not without risk. In addition, the volume of the child's own bone that can be harvested for grafting is relatively small compared with the volume afforded by BMP and manufactured allograft. For instance, in long-segment scoliosis surgeries, it would be impractical to harvest from multiple autograft donor sites to obtain enough bone graft to cover the surface needed for fusion, which spans the entire construct.

\section{Safety Concerns}

There have been anecdotal reports of complications associated with rhBMP-2 use with compressive bone formation adjacent to neural structures. ${ }^{9}$ This is particularly relevant after decompressive laminectomy or foraminotomy, in which raw bone surfaces are exposed, ${ }^{31}$ as in one of our patients. ${ }^{14}$ There is evidence to suggest that rhBMP-2 may lead to laminar reconstitution and neuroforaminal stenosis if it is implanted directly into the laminectomy site. ${ }^{29}$ Leakage of rhBMP-2 beyond the fusion area may lead to fusion of adjacent levels. Therefore, the key steps of safe rhBMP-2 usage are careful placement away from raw decompressed areas and retention of the rhBMP-2 within the fusion area by the carrier used.

It is well established that BMP plays a role in the regulation of coupled osteoblastic and osteoclastic activity. ${ }^{21,22}$ It is possible that large doses of BMP may lead to localized areas of bone resorption. ${ }^{41}$ This is not desirable in spinal fusion, and strategies to prevent this include careful control of BMP doses and controlled release from the carrier. 
It is likely, however, that any observed radiolucencies are temporary and may represent accelerated healing patterns resulting from transient stimulation of osteoclasts. ${ }^{41}$

Several studies have reported adverse local events associated with the use of rhBMP-2. Facial edema, oral erythema, pain, and rhinitis have been reported in patients who received rhBMP-2 for maxillary floor augmentation. ${ }^{4}$ The use of higher than recommended doses of rhBMP-2 has been known to cause hematoma, dysphagia, and excessive edema after anterior cervical fusion. ${ }^{34,36}$ This may be due to the enhancement by rhBMP-2 of the initial inflammatory response that is seen during bone graft incorporation. ${ }^{26}$ There was 1 case of dysphagia in our series after posterior cervical fusion with rhBMP-2; this probably was unrelated to the BMP itself and more likely related to complications in the technique of instrumentation at the craniocervical junction.

This same enhanced inflammatory response may produce a hyperinflammatory response causing wound problems, allergic reactions, or other complications. ${ }^{17}$ In our prior study, ${ }^{14}$ we did not find any deep wound healing complications, although there were 2 cases of superficial wound infection (among 19 patients). In the present long-term study, there were 2 cases of superficial wound cellulitis, 1 case of deep wound sterile seroma formation, 1 case of delayed deep wound infection from instrumentation erosion through the skin at about 2 years after surgery, and 2 cases $(4.4 \%)$ of acute ( $\leq 12$ weeks after surgery) deep wound infection associated with the administration of rhBMP-2. This rate of acute deep wound infection for a mixed cohort of idiopathic and nonidiopathic complex spine cases in the pediatric age group is consistent with the range of infection rates $(3.7 \%-8.5 \%)$ reported in the literature. $8,18,23,25,28,42$ Moreover, there was 1 case of exuberant posterior neck swelling after posterior cervical fusion with rhBMP-2 that resolved at about 3 days after surgery.

Of note, we used rhBMP-2 in a patient with a deep wound infection in whom the initial surgery for occipitocervical fusion did not include BMP. ${ }^{14}$ We removed the infected bone graft and substituted it with rhBMP-2 and demineralized bone matrix. We hypothesized that the intense inflammatory reaction caused by rhBMP-2 would stimulate wound healing and antisepsis. Two case series have documented the use of BMP in the surgical treatment of vertebral osteomyelitis, with resolution of infection in all cases and no instances of recurrence.,130 These studies provide evidence in support of the angiogenic abilities of BMP-2 and suggest that BMP, in combination with the ability of BMP to activate endothelial cells and stimulate vascular endothelial growth factor, may be the major mechanism coupling angiogenesis with osteogenesis., ${ }^{1,30}$ Theoretically, increased osteoinduction combined with increased blood supply may lead to increased local antibiotic concentrations and more rapid eradication of infection. ${ }^{1,30}$ In this way, we attempted to create an environment that strongly favors fusion, vascularity, antibiotic delivery, and eradication of infection, which occurred in our patient.

\section{Cancer Risk}

This BMP-based fusion technology has experienced a rapid increase in utilization in all types of routine spine fusion procedures including anterior cervical discectomy and fusions, posterolateral lumbar and cervical fusions, posterior and transforaminal lumbar interbody fusions, and pediatric spine fusions. ${ }^{12}$ Cahill et al. ${ }^{7}$ noted that the nationwide usage of BMP increased from $0.69 \%$ of all fusions in 2002 to $24.89 \%$ of all fusions in 2006, confirming the widespread application of this technology and its routine use in spine fusion surgery. Many patients received dosages well in excess of those studied in the FDA trials to date. There is little data available for analysis, particularly with respect to BMP dosing. Furthermore, BMP has been used in clinical practice beyond spinal fusion, including in the treatment of extremity long-bone nonunion and open fractures. $^{12}$

Recent systematic reviews and meta-analyses of the literature $^{12,16,35}$ suggest that the cancer risk associated with rhBMP-2 may be dose dependent. The cancer risk was similar in patients treated with lower doses $(4.2-4.8 \mathrm{mg})$ of rhBMP-2 $(0.7 \%)$ and control groups $(0.7 \%$ and $0.9 \%)$. However, the cancer risk was $3.8 \%$ in the higher-dose (40 mg) rhBMP-2 study. ${ }^{13}$ Applying these risk estimates to our cohort of 47 patients treated with rhBMP-2, we should have seen 1 or 2 cases of cancer at 2-year follow-up, and maybe an even higher incidence with longer follow-up (mean, 48.4 months). It is also possible that because our cohort did not receive "high doses" (i.e., $40 \mathrm{mg}$ ) of rhBMP-2, these extrapolated estimates for cancer risk are too high for our cohort; however, the relationship between dose and cancer risk has not been previously studied in the pediatric age group, and our present study does not have the statistical power to stratify varying BMP doses and cancer risk.

A recent large retrospective database study by Lad et al. ${ }^{24}$ looked at high-dose BMP and its relationship to cancer. The authors looked at BMP exposure and cancer risk at a national level by performing a retrospective crosssectional study using a large MarketScan database with at least 24 months' postoperative follow-up (mean postoperative follow-up between 49.7 and 55.6 months). Analysis showed a significant increase $(31 \%)$ in benign tumors but not malignancies. ${ }^{24}$ Moreover, there was a significantly higher number of benign tumors of the spinal meninges in the BMP group. In our study, our patients with comparable follow-up experienced neither new benign nor malignant tumor; in addition, there was no degeneration or metastasis of existing tumors.

Both BMP and BMP receptors have been isolated from human tumors. However, in vitro studies suggest that rhBMP-2 has an antiproliferative effect on human tumor colony-forming units taken from breast, ovarian, lung, and prostate cancers and embryonal cell carcinoma and cerebellar neuroectodermal tumor cell lines..$^{19,20,37,39}$ Detailed data from manufacturers' preclinical safety studies failed to demonstrate any proliferative effects of rhBMP-2 on human osteosarcoma, prostate, breast, tongue, and lung carcinoma cell lines; on the contrary, there was an inhibitory effect in all cases. ${ }^{31}$ In fact, rhBMP-2 was found to have no mutagenic activity. ${ }^{31}$ Given these available data, it seems unlikely that rhBMP-2 used to promote spinal arthrodesis has the potential to induce carcinogenesis.

Thawani et al. ${ }^{40}$ reviewed basic science and clinical data to determine the possible role of BMP in cancer. They found no definitive association between BMP and the promotion of tumorigenesis or metastasis. Our long-term ex- 
perience and clinical data with rhBMP-2 in the pediatric age group seem to support the conclusion of Thawani et al.

\section{Risk-Benefit Balance}

At the present time, the risk-benefit balance of BMP use during routine spinal fusion surgery is undetermined. Moreover, the scarcity of BMP studies in the pediatric age group makes the endeavor to establish clinical indications for BMP use in spine fusion surgery in children even more daunting. We routinely provide each patient and family with benefit and risk information, including the possibility of increased risk of future cancer with BMP use, as part of our informed consent process. We recommend that until the safety of BMP is firmly established with further study, our pediatric neurosurgery/spine surgery colleagues explicitly discuss the off-label use of BMP and its attendant risks in the pediatric age group with the patients' families and document these discussions.

We are currently analyzing BMP cost utilizing the KID database (unpublished data). The average cost of hospitalization was $\$ 59,240$ for patients receiving BMP and $\$ 53,378$ for those who did not receive BMP. The cost difference between these groups did not reach statistical significance $(p=0.057)$. Our surprising finding has implications for, and challenges, the commonly held belief that BMP use is cost prohibitive.

\section{Limitations}

Our retrospective study includes many inherent opportunities for bias, including recall bias. A significant number of patients were lost to follow-up (7 patients [12.3\%]) or died (3 patients, [5.3\%]) in our small cohort. It is conceivable that these patients may have developed a new malignancy or experienced degeneration or metastasis of an existing cancer, but this would have not been detected in our study. Without knowing the outcome in the cases of the 7 patients lost to follow-up, assuming all 7 of these patients developed cancer, the $95 \%$ CI would range from $6.4 \%$ to $24.4 \%$. Because of the significant number of patients lost to follow-up, this means that the actual risk of cancer for the entire cohort could be anywhere from $0 \%-24.4 \%$. In addition, there was no control group with outcomes that could be compared with those of our rhBMP- 2 cohort.

The assessment of cancer was based on patient or caretaker report rather than screening laboratory studies or radiological examinations. Routine screening for cancer with full-body CT or MRI is not typically done in pediatric patients, nor is it practical. Therefore, it is possible that undetected cancer is present that has not yet manifested. We acknowledge that even 2-year follow-up may be insufficient and even longer-term follow-up is needed to fully address carcinogenicity of rhBMP-2 in the pediatric population. We intend to follow up this patient population prospectively and update the clinical outcomes at a minimum of 5, 10, and 20 years after surgery.

\section{Conclusions}

It is evident that rhBMP-2 is a valuable adjunct for achieving bone fusion in spine surgery. However, little has been published regarding the use of rhBMP-2 in the pediatric population prior to our studies. We previously dem- onstrated that, in the early postoperative period, routine rhBMP-2 use is safe and efficacious, similar to its use in the adult population. A high rate of bony healing is evident with a low risk of wound healing complications; it may carry an antisepsis property as a result of its inherent ability to elicit a hyperinflammatory reaction. Judicious placement and choice of carrier is important in the setting of decompressive laminectomy to avoid unwanted bony overgrowth, restenosis, and compression of neural elements. Despite a fair number of published studies reporting an increase of cancer with use of rhBMP-2, our follow-up of at least 2 years (mean 48.4 months) in children who underwent posterior spine fusion with rhBMP-2 suggests a lack of carcinogenic potential for this agent; moreover, none of our patients had a malignant degeneration or metastasis of an existing tumor. Unfortunately, the exact incidence of cancer in our cohort of patients is uncertain due to a relatively high proportion of patients lost to follow-up. Furthermore, longer-term follow-up on the order of 5, 10, and 20 years is necessary to fully delineate the carcinogenic potential of rhBMP-2 in children.

\section{References}

1. Allen RT, Lee YP, Stimson E, Garfin SR: Bone morphogenetic protein-2 (BMP-2) in the treatment of pyogenic vertebral osteomyelitis. Spine (Phila Pa 1976) 32:2996-3006, 2007

2. Blanco JS, Sears CJ: Allograft bone use during instrumentation and fusion in the treatment of adolescent idiopathic scoliosis. Spine (Phila Pa 1976) 22:1338-1342, 1997

3. Boden SD, Zdeblick TA, Sandhu HS, Heim SE: The use of rhBMP-2 in interbody fusion cages. Definitive evidence of osteoinduction in humans: a preliminary report. Spine (Phila Pa 1976) 25:376-381, 2000

4. Boyne PJ, Marx RE, Nevins M, Triplett G, Lazaro E, Lilly LC, et al: A feasibility study evaluating rhBMP-2/absorbable collagen sponge for maxillary sinus floor augmentation. Int J Periodontics Restorative Dent 17:11-25, 1997

5. Burkus JK, Gornet MF, Dickman CA, Zdeblick TA: Anterior lumbar interbody fusion using rhBMP-2 with tapered interbody cages. J Spinal Disord Tech 15:337-349, 2002

6. Burkus JK, Gornet MF, Schuler TC, Kleeman TJ, Zdeblick TA: Six-year outcomes of anterior lumbar interbody arthrodesis with use of interbody fusion cages and recombinant human bone morphogenetic protein-2. J Bone Joint Surg Am 91:1181-1189, 2009

7. Cahill KS, Chi JH, Day A, Claus EB: Prevalence, complications, and hospital charges associated with use of bonemorphogenetic proteins in spinal fusion procedures. JAMA 302:58-66, 2009

8. Cahill PJ, Warnick DE, Lee MJ, Gaughan J, Vogel LE, Hammerberg KW, et al: Infection after spinal fusion for pediatric spinal deformity: thirty years of experience at a single institution. Spine (Phila Pa 1976) 35:1211-1217, 2010

9. Carlisle E, Fischgrund JS: Bone morphogenetic proteins for spinal fusion. Spine J 5 (6 Suppl):240S-249S, 2005

10. Carragee EJ, Hurwitz EL, Weiner BK: A critical review of recombinant human bone morphogenetic protein-2 trials in spinal surgery: emerging safety concerns and lessons learned. Spine J 11:471-491, 2011

11. Czitrom A: Biology of bone grafting and principles of bone banking, in Weinstein SL (ed): The Pediatric Spine: Principle and Practice. New York: Raven Press, 1994, pp 1285-1298

12. Devine JG, Dettori JR, France JC, Brodt E, McGuire RA: The use of rhBMP in spine surgery: is there a cancer risk? Evid Based Spine Care J 3:35-41, 2012 
13. Dimar JR II, Glassman SD, Burkus JK, Pryor PW, Hardacker JW, Carreon LY: Clinical and radiographic analysis of an optimized rhBMP-2 formulation as an autograft replacement in posterolateral lumbar spine arthrodesis. J Bone Joint Surg Am 91:1377-1386, 2009

14. Fahim DK, Whitehead WE, Curry DJ, Dauser RC, Luerssen TG, Jea A: Routine use of recombinant human bone morphogenetic protein-2 in posterior fusions of the pediatric spine: safety profile and efficacy in the early postoperative period. Neurosurgery 67:1195-1204, 2010

15. FDA Summary of Safety and Effectiveness Data (INFUSE $^{\circledR}$ Bone Graft). Silver Springs: Food and Drug Administration, 2007 (http://www.accessdata.fda.gov/cdrh_docs/ pdf5/P050053b.pdf) [Accessed December 19, 2014]

16. Fu R, Selph S, McDonagh M, Peterson K, Tiwari A, Chou R, et al: Effectiveness and harms of recombinant human bone morphogenetic protein-2 in spine fusion: a systematic review and meta-analysis. Ann Intern Med 158:890-902, 2013

17. Hansen SM, Sasso RC: Resorptive response of rhBMP2 simulating infection in an anterior lumbar interbody fusion with a femoral ring. J Spinal Disord Tech 19:130-134, 2006

18. Ho C, Skaggs DL, Weiss JM, Tolo VT: Management of infection after instrumented posterior spine fusion in pediatric scoliosis. Spine (Phila Pa 1976) 32:2739-2744, 2007

19. Iantosca MR, McPherson CE, Ho SY, Maxwell GD: Bone morphogenetic proteins- 2 and -4 attenuate apoptosis in a cerebellar primitive neuroectodermal tumor cell line. J Neurosci Res 56:248-258, 1999

20. Ide H, Yoshida T, Matsumoto N, Aoki K, Osada Y, Sugimura $\mathrm{T}$, et al: Growth regulation of human prostate cancer cells by bone morphogenetic protein-2. Cancer Res 57:5022-5027, 1997

21. Itoh K, Udagawa N, Katagiri T, Iemura S, Ueno N, Yasuda $\mathrm{H}$, et al: Bone morphogenetic protein 2 stimulates osteoclast differentiation and survival supported by receptor activator of nuclear factor- $x$ B ligand. Endocrinology 142:3656-3662, 2001

22. Kanatani M, Sugimoto T, Kaji H, Kobayashi T, Nishiyama K Fukase M, et al: Stimulatory effect of bone morphogenetic protein-2 on osteoclast-like cell formation and bone-resorbing activity. J Bone Miner Res 10:1681-1690, 1995

23. Labbé AC, Demers AM, Rodrigues R, Arlet V, Tanguay K, Moore DL: Surgical-site infection following spinal fusion: a case-control study in a children's hospital. Infect Control Hosp Epidemiol 24:591-595, 2003

24. Lad SP, Bagley JH, Karikari IO, Babu R, Ugiliweneza B, Kong M, et al: Cancer after spinal fusion: the role of bone morphogenetic protein. Neurosurgery 73:440-449, 2013

25. Linam WM, Margolis PA, Staat MA, Britto MT, Hornung R, Cassedy A, et al: Risk factors associated with surgical site infection after pediatric posterior spinal fusion procedure. Infect Control Hosp Epidemiol 30:109-116, 2009

26. Lind M, Eriksen EF, Bünger C: Bone morphogenetic protein- 2 but not bone morphogenetic protein- 4 and -6 stimulates chemotactic migration of human osteoblasts, human marrow osteoblasts, and U2-OS cells. Bone 18:53-57, 1996

27. Lu DC, Sun PP: Bone morphogenetic protein for salvage fusion in an infant with Down syndrome and craniovertebral instability. Case report. J Neurosurg 106 (6 Suppl):480-483, 2007

28. Mackenzie WG, Matsumoto H, Williams BA, Corona J, Lee C, Cody SR, et al: Surgical site infection following spinal instrumentation for scoliosis: a multicenter analysis of rates, risk factors, and pathogens. J Bone Joint Surg Am 95:800806, 2013

29. Meyer RA Jr, Gruber HE, Howard BA, Tabor OB Jr, Murakami T, Kwiatkowski TC, et al: Safety of recombinant human bone morphogenetic protein-2 after spinal laminectomy in the dog. Spine (Phila Pa 1976) 24:747-754, 1999

30. O'Shaughnessy BA, Kuklo TR, Ondra SL: Surgical treatment of vertebral osteomyelitis with recombinant human bone morphogenetic protein-2. Spine (Phila Pa 1976) 33:E132E139, 2008

31. Poynton AR, Lane JM: Safety profile for the clinical use of bone morphogenetic proteins in the spine. Spine (Phila Pa 1976) 27 (16 Suppl 1):S40-S48, 2002

32. Sandhu HS, Kanim LE, Kabo JM, Toth JM, Zeegan EN, Liu D, et al: Evaluation of rhBMP-2 with an OPLA carrier in a canine posterolateral (transverse process) spinal fusion model. Spine (Phila Pa 1976) 20:2669-2682, 1995

33. Schimandle JH, Boden SD, Hutton WC: Experimental spinal fusion with recombinant human bone morphogenetic protein-2. Spine (Phila Pa 1976) 20:1326-1337, 1995

34. Shields LB, Raque GH, Glassman SD, Campbell M, Vitaz $\mathrm{T}$, Harpring J, et al: Adverse effects associated with highdose recombinant human bone morphogenetic protein-2 use in anterior cervical spine fusion. Spine (Phila Pa 1976) 31:542-547, 2006

35. Simmonds MC, Brown JV, Heirs MK, Higgins JP, Mannion RJ, Rodgers MA, et al: Safety and effectiveness of recombinant human bone morphogenetic protein-2 for spinal fusion: a meta-analysis of individual-participant data. Ann Intern Med 158:877-889, 2013

36. Smucker JD, Rhee JM, Singh K, Yoon ST, Heller JG: Increased swelling complications associated with off-label usage of rhBMP-2 in the anterior cervical spine. Spine (Phila Pa 1976) 31:2813-2819, 2006

37. Soda H, Raymond E, Sharma S, Lawrence R, Cerna C, Gomez L, et al: Antiproliferative effects of recombinant human bone morphogenetic protein-2 on human tumor colony-forming units. Anticancer Drugs 9:327-331, 1998

38. Subach BR, Haid RW, Rodts GE, Kaiser MG: Bone morphogenetic protein in spinal fusion: overview and clinical update. Neurosurg Focus 10(4):E3, 2001

39. Tada A, Nishihara T, Kato H: Bone morphogenetic protein 2 suppresses the transformed phenotype and restores actin microfilaments of human lung carcinoma A549 cells. Oncol Rep 5:1137-1140, 1998

40. Thawani JP, Wang AC, Than KD, Lin CY, La Marca F, Park P: Bone morphogenetic proteins and cancer: review of the literature. Neurosurgery 66:233-246, 2010

41. Toth JM, Boden SD, Burkus JK, Badura JM, Peckham SM, McKay WF: Short-term osteoclastic activity induced by locally high concentrations of recombinant human bone morphogenetic protein-2 in a cancellous bone environment. Spine (Phila Pa 1976) 34:539-550, 2009

42. Vitale MG, Riedel MD, Glotzbecker MP, Matsumoto H, Roye DP, Akbarnia BA, et al: Building consensus: development of a best practice guideline (BPG) for surgical site infection (SSI) prevention in high-risk pediatric spine surgery. J Pediatr Orthop 33:471-478, 2013

\section{Author Contributions}

Conception and design: Jea. Acquisition of data: Sayama, Brayton, Briceño, Ryan. Analysis and interpretation of data: Jea. Drafting the article: Jea, Sayama, Willsey. Critically revising the article: Jea, Sayama, Chingtagumpala, Luerssen, Hwang. Reviewed submitted version of manuscript: Jea. Approved the final version of the manuscript on behalf of all authors: Jea. Administrative/technical/material support: Jea, Ryan. Study supervision: Jea.

\section{Correspondence}

Andrew Jea, Neuro-Spine Program, Division of Pediatric Neurosurgery, Department of Neurosurgery, Texas Children's Hospital, Baylor College of Medicine, 6621 Fannin St., CCC 1230.01, 12th Fl., Houston, TX 77030. email: ahjea@ texaschildrens.org. 